\title{
Effects of the PPAR $\gamma$ agonist pioglitazone on lipoprotein metabolism in patients with type 2 diabetes mellitus
}

Kazunori Nagashima, ${ }^{1}$ Carlos Lopez,, ${ }^{1}$ Daniel Donovan,, ${ }^{1}$ Colleen Ngai, ${ }^{1}$ Nelson Fontanez, ${ }^{1}$ André Bensadoun, ${ }^{2}$ Jamila Fruchart-Najib, ${ }^{3}$ Steve Holleran, ${ }^{4}$ Jeffrey S. Cohn, ${ }^{5}$ Rajasekhar Ramakrishnan, ${ }^{4}$ and Henry N. Ginsberg ${ }^{1}$

\begin{abstract}
1Department of Medicine, College of Physicians and Surgeons, Columbia University, New York, New York, USA. ${ }^{2}$ Division of Nutritional Sciences, Cornell University, Ithaca, New York, USA. ${ }^{3}$ Département d’Athérosclérose, INSERM U545, Institut Pasteur, Lille Cedex, France. ${ }^{4}$ Department of Pediatrics, College of Physicians and Surgeons, Columbia University, New York, New York, USA. ${ }^{5}$ Clinical Research Institute of Montreal, Montreal, Quebec, Canada.
\end{abstract}

\begin{abstract}
Elevated plasma levels of VLDL triglycerides (TGs) are characteristic of patients with type 2 diabetes mellitus (T2DM) and are associated with increased production rates (PRs) of VLDL TGs and apoB. Lipoprotein lipase-mediated (LPL-mediated) lipolysis of VLDL TGs may also be reduced in T2DM if the level of LPL is decreased and/or the level of plasma apoC-III, an inhibitor of LPL-mediated lipolysis, is increased. We studied the effects of pioglitazone (Pio), a PPAR $\gamma$ agonist that improves insulin sensitivity, on lipoprotein metabolism in patients with T2DM. Pio treatment reduced TG levels by increasing the fractional clearance rate (FCR) of VLDL TGs from the circulation, without changing direct removal of VLDL particles. This indicated increased lipolysis of VLDL TGs during Pio treatment, a mechanism supported by our finding of increased plasma LPL mass and decreased levels of plasma apoC-III. Lower apoC-III levels were due to reduced apoC-III PRs. We saw no effects of Pio on the PR of either VLDL TG or VLDL apoB. Thus, Pio, a PPAR $\gamma$ agonist, reduced VLDL TG levels by increasing LPL mass and inhibiting apoC-III PR. These 2 changes were associated with an increased FCR of VLDL TGs, almost certainly due to increased LPL-mediated lipolysis.
\end{abstract}

\section{Introduction}

Type 2 diabetes mellitus (T2DM) affects an estimated 17 million Americans, and its incidence is increasing rapidly both in the United States and around the world (1). T2DM is a major cause of morbidity and mortality (2), and atherosclerotic cardiovascular disease (ASCVD) plays a central role in this serious problem. Among the many risk factors for ASCVD that are prevalent in T2DM (3) is a dyslipidemia characterized by increased plasma levels of VLDL triglycerides (TGs) and apolipoprotein B100 (apoB), low levels of HDL cholesterol and apoA-I, and heterogeneity of LDL, with an increased proportion of small, dense LDL particles (4-6). Importantly, the pathophysiologic abnormalities in lipid and lipoprotein metabolism present in patients with T2DM have been closely linked to the concomitant insulin resistance present in this group $(7,8)$. Although there are medications that lower VLDL TG levels, raise HDL cholesterol, and reduce the proportion of small, dense LDL particles in people with T2DM, they do not affect the underlying insulin resistance in those individuals.

PPAR $\gamma$ agonists are new therapeutic agents for the treatment of T2DM (9-11). Because they act to improve insulin sensitivity in

Nonstandard abbreviations used: AHA, American Heart Association; CUMC, Columbia University Medical Center; $\mathrm{D}_{3}$-leucine, deuterium ${ }_{3}$-leucine; FA, fatty acid; FCR, fractional clearance rate; GCRC, General Clinical Research Center; HL, hepatic lipase; LPL, lipoprotein lipase; Pio, pioglitazone; PR, production rate; Rosi, rosiglitazone; TC, total cholesterol; T2DM, type 2 diabetes mellitus; TG, triglyceride; TZD, thiazolidinedione.

Conflict of interest: Takeda Pharmaceuticals North America Inc., the manufacturer and distributor of pioglitazone, supported this study. The study was conceived and conducted by the investigators, who had complete control of the primary data, the analyses, and the writing of this manuscript.

Citation for this article: J. Clin. Invest. 115:1323-1332 (2005).

doi:10.1172/JCI200523219. muscle, liver, and fat (12-15), they may be active against many of the nonglucose abnormalities present in patients with T2DM (16). The 2 available thiazolidinedione (TZD) PPAR $\gamma$ agonists, pioglitazone (Pio) and rosiglitazone (Rosi), both demonstrate efficacy in the treatment of some aspects of diabetic dyslipidemia: each elevates HDL cholesterol concentrations and increases LDL particle size. However, they have variable effects on LDL cholesterol concentrations, and while Pio reduces plasma TG concentrations, Rosi treatment either has no effect or is associated with increases in plasma TG levels (17-19). In an initial study to determine the mechanisms whereby a PPAR $\gamma$ agonist might lower plasma TG concentrations and raise plasma HDL cholesterol levels, we examined the metabolism of VLDL, IDL, and LDL apoB, VLDL TGs, HDL apoA-I, and plasma apoC-III in patients with T2DM before and during treatment with Pio.

\section{Results}

The clinical characteristics of patients at the start of the placebo treatment period (after 2 weeks of diet counseling) are presented in Table 1 . The patients' ages ranged from 39 to 71 years. BMI varied from 23.9 to $41.1 \mathrm{~kg} / \mathrm{m}^{2}$, with a mean \pm SD of $30.5 \pm 6.3$ $\mathrm{kg} / \mathrm{m}^{2}$. TG levels at the start of placebo treatment ranged from 114 to $416 \mathrm{mg} / \mathrm{dl}$, with a mean of $216.4 \pm 95.6 \mathrm{mg} / \mathrm{dl}$, and HDL cholesterol varied from 25 to $38 \mathrm{mg} / \mathrm{dl}$, with a mean of $31.0 \pm 4.7$ $\mathrm{mg} / \mathrm{dl}$. There were 5 patients with the apoE $3 / 3,2$ with the apoE $4 / 3$, and 1 with the apoE 4/4 genotype. All 8 patients were taking sulfonylurea in combination with metformin at the start of the placebo period and continued those medications at the same dosage throughout the placebo period. Pio treatment was $30 \mathrm{mg} / \mathrm{d}$ for 4 weeks, followed by $45 \mathrm{mg} / \mathrm{d}$ for 10-12 weeks, depending on individual patients' schedules. 


\section{Table 1}

Patient characteristics at baseline

$\begin{array}{lccccccc}\text { Patient } & \text { Sex } & \text { Age } & \text { BMIA }^{\text {A }} & \text { TC }^{B} & \text { TGs }^{\text {B }} & \text { HDLC }^{B} & \text { LDLCB,C }^{\text {B }} \\ 1 & \text { F } & 62 & 24.5 & 149 & 235 & 26 & 76 \\ 2 & \mathrm{~F} & 71 & 35.9 & 250 & 238 & 31 & 171 \\ 3 & \mathrm{~F} & 63 & 35.8 & 151 & 125 & 37 & 89 \\ 4 & \mathrm{M} & 41 & 27.1 & 229 & 251 & 30 & 149 \\ 5 & \mathrm{~F} & 54 & 23.9 & 202 & 182 & 25 & 141 \\ 6 & \mathrm{M} & 53 & 28.8 & 160 & 114 & 32 & 105 \\ 7 & \mathrm{~F} & 45 & 41.1 & 241 & 416 & 29 & \text { ND } \\ 8 & \mathrm{M} & 39 & 26.9 & 167 & 170 & 38 & 95\end{array}$

All data were collected at the start of the placebo period. ${ }^{\mathrm{A}} \mathrm{BMI}$ is expressed as weight $(\mathrm{kg}) /$ height $(\mathrm{m})^{2}$. BValues for all lipids are expressed as mg/dl. HDLC, HDL cholesterol; LDLC, LDL cholesterol. CLDLC was estimated using the Friedewald equation. There was no estimate for patient no. 7, whose TG level was greater than $400 \mathrm{mg} / \mathrm{dl}$.

During the study, home monitoring of blood glucose levels, together with measures of $\mathrm{HbA} 1 \mathrm{c}$ at the time of the first lipoprotein turnover studies (hereafter, TS1) and after 6 and 12 weeks of Pio treatment, allowed for titration of the sulfonylurea dose. During Pio treatment, 7 patients discontinued use of the sulfonylurea they had been taking, while the eighth patient reduced the dose. As noted in Methods, the dose of metformin was not changed in any patient. The mean $\mathrm{HbA1}$ c level at the end of the placebo period (at TS1) was $6.58 \% \pm 0.98 \%$ and after the second lipoprotein turnover studies (TS2; after 14-16 weeks of Pio treatment) was $6.09 \pm 0.57$ $(P<0.05)$. Overall, glycemic control was excellent during both study periods. Liver function tests were monitored every 3 weeks; there were no elevations of either alanine aminotransferase or aspartate aminotransferase. Weight was recorded at every visit; the mean weight of the 8 patients was $81.2 \pm 14.4 \mathrm{~kg}$ at the start of the placebo period, $80.8 \pm 14.2 \mathrm{~kg}$ at TS1, and $80.2 \pm 14.6 \mathrm{~kg}$ at TS2. Thus, weight was stable throughout the study.

Mean plasma levels ( \pm SD) of glucose, insulin, fatty acids (FAs), and adiponectin during the placebo and Pio treatment periods are presented in Figure 1. The placebo values are single fasting blood samples obtained at the start of placebo treatment (fasting samples were not available at the time of TS1), while the Pio values are the means of 2 fasting blood samples obtained at the last 2 outpatient visits during treatment (either weeks 12 and 13 or weeks 12 and 15). Fasting plasma glucose levels (Figure 1A) fell from $139.9 \pm 34.1 \mathrm{mg} / \mathrm{dl}$ to $104.6 \pm 22.9 \mathrm{mg} / \mathrm{dl}$ during treatment with Pio (mean change $\pm \mathrm{SD}, 35.3 \pm 38 \mathrm{mg} / \mathrm{dl} ; P<0.05$ ). This change was consistent with the change in HbA1c levels noted above. Plasma insulin levels (Figure 1B) tended to fall in response to Pio treatment, from $19.7 \pm 15.7 \mu \mathrm{U} / \mathrm{ml}$ to $12.7 \pm 5.7$ $\mu \mathrm{U} / \mathrm{ml}(6.9 \pm 10.8 \mu \mathrm{U} / \mathrm{ml} ; P=0.08)$. Both plasma FA (Figure $1 \mathrm{C}$ ) and adiponectin levels (Figure 1D) responded to Pio as expected. Mean plasma FA levels fell $28 \%$, from $0.43 \pm 0.12 \mathrm{mEq} / \mathrm{l}$ at the start of placebo treatment to $0.31 \pm 0.10 \mathrm{mEq} / \mathrm{l}$ at the end of Pio treatment $(0.12 \pm 0.15 \mathrm{mEq} / 1 ; P<0.05)$, and mean adiponectin levels increased almost 3-fold, from $5.0 \pm 1.6 \mathrm{mg} / \mathrm{ml}$ to $14.6 \pm 5.6$ $\mathrm{mg} / \mathrm{ml}(9.6 \pm 4.3 \mathrm{mg} / \mathrm{ml} ; P<0.001)$. Overall, these data support the conclusion that Pio treatment significantly increased insulin sensitivity in these patients.

Figure 2 shows the effects of Pio treatment on plasma lipid levels. The group means are depicted for TS1 and for TS2. Each patient's individual results were the means of 18 timed samples obtained dur- ing the 48-hour turnover protocol. There were significant reductions in levels of both plasma TGs, which fell $89 \pm 27 \mathrm{mg} / \mathrm{dl}$ (31\%; $P<0.01)$, and VLDL TGs, which fell $58 \pm 31 \mathrm{mg} / \mathrm{dl}(30 \% ; P=0.01)$ (Figure $2 \mathrm{~A})$. There was an increase in HDL cholesterol level of $3.5 \pm 3.4 \mathrm{mg} / \mathrm{dl}$ $(14 \% ; P=0.02)$ (Figure 2B) after TS2 compared with TS1. Total cholesterol (TC) (Figure 2A) and LDL cholesterol (Figure 2B) levels did not change significantly on Pio versus placebo treatment. Although we cannot rule out an effect of reduced doses of sulfonylurea on plasma lipid levels, it seems very unlikely that lowering the dose of sulfonylurea, an agent that has minimal effects on lipid levels, would lead to improved TG and HDL concentrations.

Table 2 shows the individual and mean values of VLDL TG fractional clearance rates (FCRs) and production rates (PRs) at the end of TS1 and at the end of TS2. Concomitant with the reduction in VLDL TGs of 30\% during Pio treatment compared with placebo, the FCRs of VLDL TGs increased in 7 of 8 patients. The mean FCR of VLDL TGs during Pio treatment was $0.389 \pm 0.19$ $\mathrm{h}^{-1}$; this was an increase of $0.143 \pm 0.13 \mathrm{~h}^{-1}(57 \% ; P=0.015)$ from the mean FCR of $0.247 \pm 0.12 \mathrm{~h}^{-1}$ at the end of the placebo period. There was no significant effect of Pio treatment on VLDL TG PR (placebo, $29.1 \pm 5.3 \mathrm{mg} / \mathrm{kg} / \mathrm{h}$ vs. Pio, $31.3 \pm 5.8 \mathrm{mg} / \mathrm{kg} / \mathrm{h}$ ). The group mean values for both VLDL TG FCR and PR during each period are presented graphically in Figure 3, A and B.

Figure $4 \mathrm{~A}$ presents the group mean values for apoB in total plasma and in each lipoprotein fraction during TS1 and TS2. Pio treatment had no significant effect on apoB levels in plasma or in any of the lipoprotein fractions. In particular, despite a $30 \%$ reduction in VLDL TG levels, there was no effect of Pio treatment on VLDL apoB levels. The individual and group mean FCRs and PRs for VLDL, IDL, and LDL apoB during both TS1 and TS2 are shown in Table 3. Concomitant with the increase in VLDL TG FCR on Pio, there was a trend toward an increase in
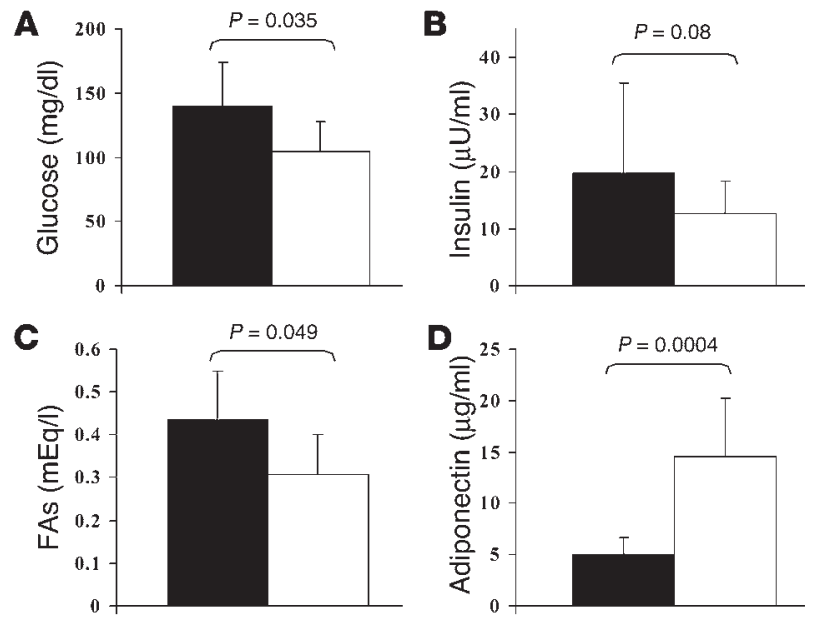

\section{Figure 1}

Mean levels \pm SD of fasting glucose (A), insulin (B), FAs (C), and adiponectin (D) in patients during placebo (black bars) and Pio (white bars) treatments. The placebo values are single fasting blood samples obtained at the start of placebo treatment, while the Pio values are the means of 2 fasting blood samples obtained at the last 2 outpatient visits during treatment (either weeks 12 and 13 or weeks 12 and 15). Pio treatment was associated with reductions in plasma glucose, insulin, and FA levels, while adiponectin levels increased during Pio treatment. 

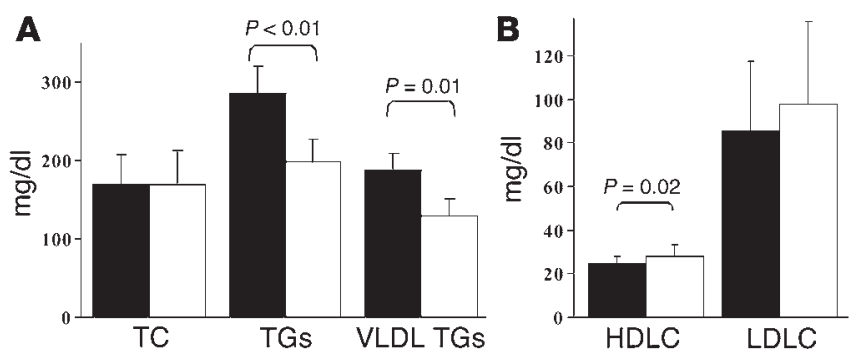

Figure 2

Mean plasma and lipoprotein lipid levels \pm SD during placebo (black bars) and Pio (white bars) treatments. Each patient's results were the means of 18 timed samples obtained during the 48-hour turnover protocol. Pio treatment was associated with significant reductions in plasma and VLDL TG levels (A) and a significant increase in HDL cholesterol (HDLC) concentrations (B). There was no change in total or LDL cholesterol levels during Pio compared with placebo treatment.

VLDL apoB FCR during Pio treatment (3.92 \pm 1.29 vs. $4.53 \pm 1.59$ $\mathrm{d}^{-1}$; mean change $\left.\pm \mathrm{SD} ; 0.61 \pm 0.73 \mathrm{~d}^{-1} ; P=0.052\right)$. VLDL apoB PR was unchanged by Pio treatment (placebo, $29.8 \pm 5.6$ vs. Pio, $32.6 \pm 6.2 \mathrm{mg} / \mathrm{kg} / \mathrm{d}$ ). IDL and LDL apoB FCRs and PRs were also not significantly affected by Pio therapy. The mean apoB FCRs and PRs for VLDL, IDL, and LDL during placebo and Pio treatment are depicted graphically in Figure 4, B and C.

Direct removal of VLDL apoB was the same during treatment with placebo and Pio (19.5 \pm 5.2 vs. $21.6 \pm 5.5 \mathrm{mg} / \mathrm{kg} / \mathrm{d}$; NS $)$, and the fraction of VLDL converted to LDL, which was $34.8 \% \pm 7.9 \%$ during placebo, was unchanged during Pio treatment $(34.1 \% \pm 8.1 \%)$.

The data presented above suggest that Pio treatment increased the efficiency of VLDL TG clearance, probably by a lipolytic pathway. To gain further insight into this possibility, we measured the serum or plasma concentrations of lipoprotein lipase (LPL), hepatic lipase (HL), apoC-III, and apoA-V during each study period. LPL is synthesized in, and secreted from, adipose tissue and muscle. After secretion, LPL binds to heparan sulfate proteoglycans on the luminal surface of endothelial cells, where it can interact with TGrich lipoproteins and initiate lipolysis. In nonheparinized (preheparin) serum, low but measurable amounts of LPL are present and probably reflect rates of LPL synthesis. Two samples, obtained at 8 and 10 hours of each lipoprotein turnover study, were analyzed, and the mean of the 2 values obtained during TS1 were compared with those obtained during TS2. LPL mass was $82.3 \pm 23.3 \mathrm{ng} / \mathrm{ml}$ during TS1 and increased significantly during TS2, when the mean was $101.7 \pm 20.0 \mathrm{ng} / \mathrm{ml}$ (difference, $19.4 \pm 16.7 \mathrm{ng} / \mathrm{ml} ; P=0.013$ ). LPL mass increased in 7 of 8 patients during Pio treatment, and the individual values are shown in Table 4. Thus, Pio therapy was associated with increased preheparin serum LPL mass. The preheparin serum mass of HL, which is synthesized in the liver and can act as a TG lipase in the hepatic capillary bed, was unaffected by Pio treatment (TS1, $8.6 \pm 2.0 \mathrm{ng} / \mathrm{ml}$; TS2, $8.1 \pm 2.7 \mathrm{ng} / \mathrm{ml} ; P=0.41)$.

ApoC-III, which has been shown to inhibit LPL-mediated lipolysis of VLDL TG (20), was reduced significantly by Pio treatment from a mean plasma level of $21.8 \pm 5.7 \mathrm{mg} / \mathrm{dl}$ during TS1 to $17.4 \pm 6.8 \mathrm{mg} / \mathrm{dl}$ during TS2 (difference, $4.3 \pm 5.0 \mathrm{mg} / \mathrm{dl}$; $P<0.05$ ) (Figure 5A). ApoC-III levels in plasma fell in 7 of 8 subjects during Pio treatment. A fall in plasma apoC-III levels could have resulted from either a reduction in hepatic secretion of apoC-III into plasma or an increase in the fractional clearance of apoC-III from the circulation. Stable isotope turnover studies demonstrated that the reduction in plasma apoC-III concentration was due to a $34 \%$ fall in plasma apoC-III PR during Pio treatment compared with placebo $(3.87 \pm 1.16 \mathrm{vs} .2 .52 \pm 1.87 \mathrm{mg} /$ $\mathrm{kg} / \mathrm{d}$; difference, $1.34 \pm 1.38 \mathrm{mg} / \mathrm{kg} / \mathrm{d} ; P=0.03)$. There was a nonsignificant trend toward a lower fractional synthetic rate (FSR) for apoC-III on Pio ( $0.397 \pm 0.10$ vs. $0.294 \pm 0.12 \mathrm{~d}^{-1}$; difference, $0.10 \pm 0.13 ; P=0.06)$. These data are shown in Figure 5, B and C.

ApoA- $\mathrm{V}$ is a recently discovered apolipoprotein that is involved in TG metabolism. Mice lacking apoA-V have hypertriglyceridemia, while overexpression of the gene encoding apoA-V is associated with lower plasma TG levels (21). Pio treatment had no effect on levels of either total plasma apoA-V $(11.4 \pm 10.0 \mathrm{ng} / \mathrm{ml}$ at the end of placebo vs. $9.1 \pm 6.2 \mathrm{ng} / \mathrm{ml}$ at the end of Pio treatment) or nonHDL apoA-V $(5.8 \pm 5.9 \mathrm{ng} / \mathrm{ml}$ at the end of placebo vs. $4.4 \pm 3.2$ $\mathrm{ng} / \mathrm{ml}$ at the end of Pio treatment).

Individual HDL apoA-I levels, HDL apoA-I FSRs, and HDL apoA-I PRs are presented in Table 5, and group changes in HDL apoA-I levels, FSR, and PR are shown in Figure 6. Pio therapy was associated with increases in HDL cholesterol in 7 of 8 patients, with a mean increase of $14.3 \%$ (placebo, $24.7 \pm 3.5 \mathrm{mg} / \mathrm{dl}$ vs. Pio, $28.2 \pm 5.0$ $\mathrm{mg} / \mathrm{dl} ; P<0.05)$. ApoA-I concentrations increased in 5 of 8 patients, but the mean level of apoA-I during Pio treatment $(74.5 \pm 9.9 \mathrm{mg} /$ dl) was not significantly higher than the mean level during placebo $(68.7 \pm 8.4 \mathrm{mg} / \mathrm{dl})(P=0.12)$. There were also no differences in either the apoA-I FSR or PR at TS1 compared with TS2.

TZDs appear to increase mean LDL size (17). Although we did not directly assess LDL particle size, we did calculate the ratio of cholesterol to apoB in LDL, which is a surrogate for direct LDL size measurement. The ratios are the mean values of 6 samples of LDL isolated during each turnover study. During TS1, the mean LDL cholesterol/LDL apoB ratio was $1.34 \pm 0.10$; during TS2, the ratio was $1.42 \pm 0.17$. There was no statistically significant effect of Pio on this measure of LDL particle size $(P=0.10)$.

\section{Discussion}

Hypertriglyceridemia is a central component of diabetic dyslipidemia $(4,5)$ and is also an integral pathophysiologic component of the insulin resistance syndrome $(7,22)$ (often referred to as syn-

\section{Table 2}

Individual and mean VLDL TG FCR and PR during placebo and Pio treatments

\begin{tabular}{lcccr} 
Patient & \multicolumn{2}{c}{ FCR $\left(\mathbf{h}^{-1}\right)$} & \multicolumn{2}{c}{ PR $(\mathbf{m g} / \mathbf{k g} / \mathbf{h})$} \\
& TS1 & TS2 & TS1 & TS2 \\
1 & 0.128 & 0.158 & 20.3 & 29.4 \\
2 & 0.206 & 0.223 & 27.5 & 28.4 \\
3 & 0.361 & 0.483 & 34.1 & 27.0 \\
4 & 0.132 & 0.262 & 25.1 & 30.3 \\
5 & 0.232 & 0.593 & 30.1 & 40.8 \\
6 & 0.291 & 0.600 & 26.9 & 29.5 \\
7 & 0.166 & 0.232 & 32.2 & 25.1 \\
8 & 0.458 & 0.563 & 36.8 & 39.8 \\
Mean & 0.247 & 0.389 & 29.1 & 31.3 \\
SD & 0.117 & 0.188 & 5.3 & 5.8 \\
$P$ & \multicolumn{2}{c}{0.015} & \multicolumn{2}{c}{ NS }
\end{tabular}

FCR, fractional catabolic rate in pool per hour; PR into plasma VLDL is expressed as $\mathrm{mg} / \mathrm{kg} / \mathrm{h}$. 

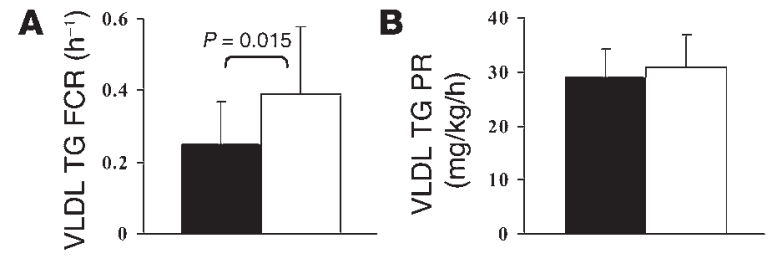

Figure 3

Mean VLDL TG FCR (A) and PR (B) during placebo (black bars) and Pio (white bars) treatments. The results were derived from injections of $\left[{ }^{3} \mathrm{H}\right]$ glycerol as a precursor of VLDL TG. Pio treatment was associated with a significant increase in VLDL TG FCR and no effect on VLDL TG PR.

drome X or the metabolic syndrome). Although very low levels of LPL activity, in association with marked hypertriglyceridemia and hyperchylomicronemia, have been observed in decompensated patients with T2DM (23), the prevailing view is that moderate hypertriglyceridemia in the typical patient with T2DM results from increased assembly and secretion of TG-rich apoB-containing lipoproteins $(4,24,25)$. In fact, LPL in patients with T2DM is usually normal or only slightly decreased. On the other hand, overproduction of apoB-containing lipoproteins, including VLDL, has been demonstrated $(26,27)$ in several in vivo kinetic studies of patients with insulin resistance with or without T2DM.

Increased assembly and secretion of VLDL in T2DM has been attributed to several concomitant abnormalities. There is strong evidence that increased plasma FA flux to the liver, resulting from increased hormone-sensitive lipase-mediated release of FAs from adipose tissue of insulin-resistant individuals, "drives" hepatic TG synthesis and the assembly of VLDL (28-31). Indeed, mice lacking hormone-sensitive lipase have reduced plasma levels of FAs and reduced rates of TG secretion from the liver (32). Further, we have shown that intravenous infusion of albumin-bound FAs increases secretion of VLDL from livers of normal mice (33). Importantly, Lewis et al. demonstrated that in healthy humans, increasing plasma FA flux by infusion of a TG emulsion and heparin increased VLDL secretion from the liver (34). Insulin-mediated degradation of nascent apoB appears to be a second important regulator of the assembly and secretion of VLDL from healthy livers $(35,36)$, and defects in this pathway, leading to increased apoB secretion, have been demonstrated in insulin-resistant rodent models $(37,38)$ and in humans $(39,40)$. De novo lipogenesis by the liver is clearly important for VLDL secretion in rodents, and there is increasing evidence for a role in humans as well (41-43). Recent studies in rodents suggest that insulin can stimulate lipogenesis by increasing SREBP1c gene expression $(44,45)$ via an IRS/PI3K-independent pathway (46), although there are now conflicting data regarding this issue (47-49). However, if insulin can stimulate lipogenesis in an otherwise insulin-resistant liver, then insulin resistance-induced hyperinsulinemia could be another driving force for increased VLDL assembly and secretion.

Based on the above, we expected that our patients with T2DM would have elevated rates of secretion of VLDL TGs and VLDL apoB during placebo. Indeed, consistent with published data from studies of normal subjects in several laboratories $(50,51)$, including our own (20), that is what we found. We also expected that Pio treatment would lower plasma TG levels by decreasing the assembly and secretion of both VLDL TGs and VLDL apoB by its ability to: (a) improve adipose tissue sensitivity to insulin, thereby reducing FA flux from adipose tissue to the liver $(15,52,53)$; (b) reduce plasma insulin levels, thereby lowering hepatic lipogenesis $(44,45$, $54)$; and (c) improve hepatic insulin sensitivity, thereby increasing degradation of nascent apoB $(35,36,55)$. We found instead that although plasma TG levels fell significantly, there was no change in hepatic secretion of either VLDL TGs or apoB. In fact, increased fractional removal of VLDL TGs accounted for the reduction in plasma TG concentrations observed during Pio therapy.

The increased fractional removal of VLDL TGs we observed could have resulted from increased LPL-mediated VLDL TG hydrolysis or from increased fractional clearance of VLDL particles from plasma. Our finding that Pio treatment was associated with an increased FCR for VLDL TGs, along with the fact that there was no change in direct removal of VLDL apoB compared with placebo treatment, leaves increased lipolysis of VLDL TGs - with concomitant increased conversion of VLDL particles to more dense apoB lipoproteins - as the most likely explanation for the fall in plasma TG levels. This conclusion is supported by the data indicating that VLDL apoB FCRs may have also increased. Although we did not measure either tissue or postheparin plasma LPL activity, we did find that preheparin plasma LPL mass was significantly increased by Pio treatment. LPL is a PPAR $\gamma$-responsive gene (56), and the PPAR $\gamma$ agonist troglitazone has been demonstrated to increase postheparin plasma LPL activity (57) and both preheparin (58) and postheparin (59) LPL mass in subjects with diabetes and/or insulin resistance. In the latter study, troglitazone significantly lowered plasma TG levels at the same time (59). Preheparin LPL mass had modest but significant correlations with plasma TG levels in 2 other studies $(60,61)$. Pio treatment increased LPL mRNA in white adipose tissue of brown adipose tissue-deficient mice,
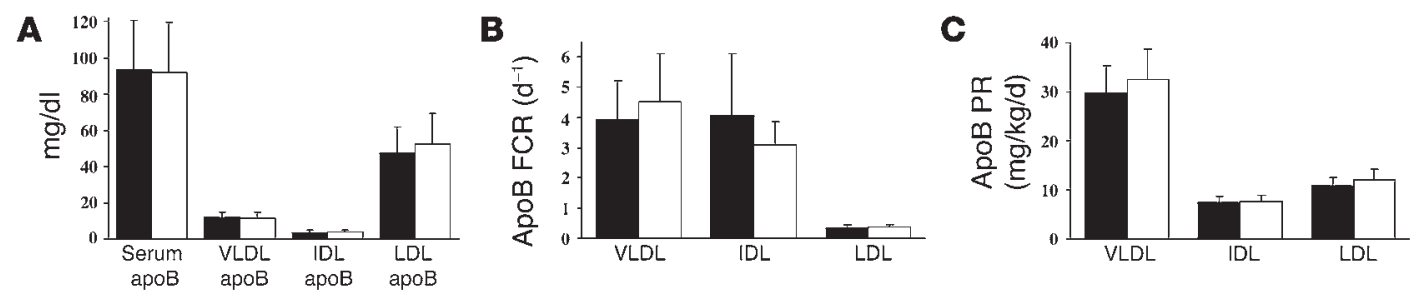

\section{Figure 4}

Mean plasma and lipoprotein apoB levels \pm SD during placebo (black bars) and Pio (white bars) treatments (A). Each patient's results were the means of 6 timed samples obtained during the 48-hour turnover protocol. Pio treatment had no effect on apoB concentration in whole plasma or in individual lipoproteins. Mean VLDL, IDL, and LDL apoB FCR (B) and PR (C) during placebo and Pio treatments. These results were derived from injection of $\mathrm{D}_{3}$-leucine and deuterium-labeled phenylalanine as precursors of apoB. Pio treatment did not affect the FCRs or the PRs of the apoB-containing lipoproteins. 
Table 3

Individual and mean VLDL, IDL, and LDL apoB FCRs and PRs during placebo and Pio treatments

\begin{tabular}{|c|c|c|c|c|c|c|c|c|c|c|c|c|}
\hline \multirow[t]{3}{*}{ Patient } & \multicolumn{4}{|c|}{ VLDL } & \multicolumn{4}{|c|}{ IDL } & \multicolumn{4}{|c|}{ LDL } \\
\hline & \multicolumn{2}{|c|}{ FCR $\left(d^{-1}\right)$} & \multicolumn{2}{|c|}{$P R$ (mg/kg/d) } & \multicolumn{2}{|c|}{ FCR ( $\left.d^{-1}\right)$} & \multicolumn{2}{|c|}{$P R(\mathrm{mg} / \mathrm{kg} / \mathrm{d})$} & \multicolumn{2}{|c|}{$\operatorname{FCR}\left(d^{-1}\right)$} & \multicolumn{2}{|c|}{$P R(\mathrm{mg} / \mathrm{kg} / \mathrm{d})$} \\
\hline & TS1 & TS2 & TS1 & TS2 & TS1 & TS2 & TS1 & TS2 & TS1 & TS2 & TS1 & TS2 \\
\hline 1 & 2.69 & 3.20 & 20.5 & 29.6 & 2.47 & 2.41 & 6.5 & 7.2 & 0.40 & 0.45 & 9.8 & 12.0 \\
\hline 2 & 3.20 & 2.82 & 28.2 & 29.7 & 2.03 & 2.58 & 8.7 & 9.6 & 0.24 & 0.22 & 11.9 & 11.3 \\
\hline 3 & 5.23 & 5.14 & 35.0 & 28.5 & 5.27 & 2.89 & 8.3 & 6.1 & 0.47 & 0.44 & 9.9 & 8.5 \\
\hline 4 & 2.84 & 3.59 & 25.2 & 31.2 & 3.56 & 2.72 & 5.1 & 7.5 & 0.27 & 0.37 & 7.8 & 15.8 \\
\hline 5 & 3.96 & 5.76 & 30.6 & 43.0 & 3.97 & 3.13 & 7.5 & 8.2 & 0.35 & 0.30 & 11.7 & 13.2 \\
\hline 6 & 4.84 & 6.29 & 27.5 & 30.9 & 8.23 & 3.44 & 8.5 & 5.9 & 0.43 & 0.43 & 11.6 & 10.2 \\
\hline 7 & 2.64 & 2.85 & 33.0 & 26.3 & 2.21 & 2.81 & 7.6 & 8.7 & 0.31 & 0.30 & 12.7 & 12.4 \\
\hline 8 & 5.99 & 6.59 & 38.0 & 41.5 & 4.77 & 4.82 & 7.5 & 8.0 & 0.42 & 0.42 & 12.0 & 13.0 \\
\hline Mean & 3.92 & 4.53 & 29.8 & 32.6 & 4.06 & 3.10 & 7.5 & 7.7 & 0.36 & 0.37 & 10.9 & 12.1 \\
\hline SD & 1.29 & 1.59 & 5.6 & 6.2 & 2.06 & 0.76 & 1.2 & 1.3 & 0.08 & 0.08 & 1.6 & 2.2 \\
\hline$P$ & \multicolumn{2}{|c|}{0.052} & \multicolumn{2}{|c|}{ NS } & \multicolumn{2}{|c|}{ NS } & \multicolumn{2}{|c|}{ NS } & \multicolumn{2}{|c|}{ NS } & \multicolumn{2}{|c|}{ NS } \\
\hline
\end{tabular}

FCR: fractional clearance rate in pool per day $\left(\mathrm{d}^{-1}\right)$; PR into each lipoprotein fraction is expressed as $\mathrm{mg} / \mathrm{kg} / \mathrm{d}$.

and this was accompanied by a reduction in plasma TG levels and increases in postheparin plasma LPL activity (62). A recent study demonstrated increases in adipose tissue LPL mRNA levels in patients with T2DM treated with Pio (63). Together with our kinetic results (including the apoC-III data discussed below), these previously published data offer strong support for increased LPL-mediated lipolysis of VLDL TGs as the key component of the TG-lowering effects of Pio therapy.

ApoC-III, a major component of VLDL, inhibits the activity of LPL in vitro (64) and in vivo (20), and increased expression of apoC-III in a transgenic mouse was associated with hypertriglyceridemia (65). We found that plasma apoC-III levels fell in conjunction with reduced secretion of apoC-III during Pio treatment, and reduced concentrations of apoC-III are associated with more efficient LPL-mediated lipolysis $(20,66)$. To our knowledge, this is the first demonstration of decreased apoC-III secretion during Pio treatment, and it is of significant interest. The mechanism whereby Pio reduces apoC-III secretion remains to be determined, although several published studies provide important insights. First, it is known that apoC-III gene expression is suppressed by PPAR $\alpha$ agonists (67), possibly via direct binding of activated PPAR $\alpha$, in a nonproductive manner, to a hepatocyte nuclear factor-4 site in the apoC-III promoter (68, 69). PPAR $\alpha$ agonists may also suppress apoC-III gene expression indirectly through Rev-erb $\alpha$ antagonism of retinoic acid-related orphan receptor $\alpha(\mathrm{ROR} \alpha)$, a transcriptional activator of apoC-III $(68,70)$. Malmendier et al. reported that fenofibrate, a PPAR $\alpha$ agonist, lowered apoC-III production in humans (71). Effects of PPAR $\gamma$ agonists on apoC-III gene expression have not been reported previously, although both Pio and Rosi have been shown to bind to and stimulate a PPAR $\alpha$ reporter gene in transactivation assays (72). On the other hand, the recent report by Altomonte et al. (73) indicated that insulin's ability to inhibit apoC-III gene expression was via inhibition of Foxo 1 binding to the putative insulin response element of apoC-III $(74,75)$ in hepatocytes. This novel finding potentially links defective insulin signaling to increased apoC-III gene expression, increased apoC-III levels in blood, and hypertriglyceridemia. This schema is consistent with recent studies demonstrating a correlation between insulin resistance and apoC-III production in humans (76). More importantly, these data suggest that Pio, by increasing hepatic insulin sensitivity (77), could reduce expression of the
apoC-III gene. This would provide a PPAR $\gamma$-mediated mechanism for our finding of reduced apoC-III production during Pio treatment.

ApoA- $\mathrm{V}$ is a recently identified apolipoprotein that appears to play an important role in TG metabolism (21), and several studies have shown that polymorphisms in the apoA-V gene are associated with hypertriglyceridemia $(21,78)$. We did not find any effect of Pio on apoA-V levels in our patients, although the distribution of apoA-V was shifted to the non-HDL fraction, consistent with hypertriglyceridemia. ApoA-V is regulated by PPAR $\alpha$ (79), and the lack of effect of Pio on apoA-V levels argues against any significant PPAR $\alpha$ activity of Pio in our patients.

Low levels of HDL cholesterol are characteristic of individuals with insulin resistance with or without T2DM (4). Consistent with published studies of each of the TZDs $(17,80)$, treatment with Pio raised HDL cholesterol levels $14 \%$ in our study. The basis of this increase is unclear at this time; our results do not show an increase in apoA-I PR, or a fall in apoA-I FSR, during Pio therapy. ApoA-I synthesis is regulated by several transcription factors, including PPAR $\alpha$ (67); there is no evidence that PPAR $\gamma$ plays a role in apoA-I synthesis in vivo, although both Pio and Rosi have been reported

Table 4

Individual and mean levels of LPL and HL mass during placebo and Pio treatments

\begin{tabular}{lrrrr}
\hline \multirow{2}{*}{ Patient } & \multicolumn{2}{c}{ LPL $(\mathbf{n g} / \mathrm{ml})$} & \multicolumn{2}{c}{ HL $(\mathbf{n g} / \mathrm{ml})$} \\
& \multicolumn{1}{c}{ TS1 } & \multicolumn{1}{c}{ TS2 } & TS1 & TS2 \\
& 97.4 & 121.9 & 7.3 & 8.5 \\
2 & 59.4 & 101.1 & 9.3 & 9.1 \\
3 & 83.6 & 100.5 & 8.5 & 6.4 \\
4 & 112.3 & 96.7 & 10.8 & 7.3 \\
5 & 71.4 & 89.2 & 12.2 & 14.2 \\
6 & 114.0 & 136.6 & 6.8 & 6.8 \\
7 & 55.1 & 70.4 & 7.0 & 6.4 \\
8 & 65.1 & 97.2 & 7.2 & 6.1 \\
Mean & 82.3 & 101.7 & 8.6 & 8.1 \\
SD & 23.3 & 20.0 & 2.0 & 2.7 \\
$P$ & \multicolumn{2}{c}{0.013} & \multicolumn{2}{c}{0.41} \\
\hline
\end{tabular}



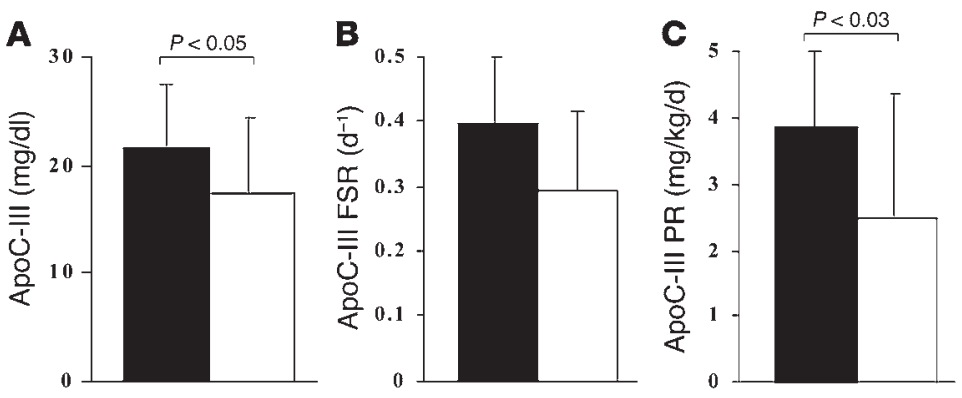

\begin{abstract}
Figure 5
Mean levels of plasma apoC-III \pm SD $(\mathbf{A})$, mean plasma apoC-III FSR (B), and mean plasma apoC-III PR (C) during placebo (black bars) and Pio (white bars) treatments. The results were derived from injection of $\mathrm{D}_{3}$-leucine as a precursor of apoC-III. Pio treatment resulted in significant reductions in plasma apoC-III level and apoC-III PR.
\end{abstract}

TGs in patients with well-controlled T2DM. Reductions in VLDL TG levels were associated with increased efficiency of TG clearance from plasma, almost certainly mediated by increased LPL-associated lipolysis. Our

to stimulate apoA-I secretion from HepG2 cells (72). It is possible that the modest increase in HDL cholesterol we observed during Pio treatment resulted from reduced cholesterol ester transfer protein (CETP)-mediated exchange of VLDL TGs for HDL cholesterol, concomitant with the Pio-associated fall in VLDL TG levels. If Pio treatment reduced the mass or activity of HL, which also has phospholipase activity, there might be an associated increase in the levels of HDL. There are no published data regarding the effect of PPAR $\gamma$ agonists on HL activity, but we found no change in HL mass in preheparin serum during Pio versus placebo treatment. Finally, it has been suggested that PPAR $\gamma$ signaling may play a role in stimulating expression of the gene encoding ABCA1 (81), which could increase the flux of cholesterol from cells onto nascent apoA-I (82). If PPAR $\gamma$ were involved in regulating $A B C A 1$ gene expression in the liver, additional effects on plasma HDL cholesterol levels might be seen.

The basis for our finding that Pio treatment had no effect on VLDL secretion deserves some further examination. Pio treatment improved insulin sensitivity, as reflected in the parallel falls of plasma insulin and glucose levels, and the dramatic rise in adiponectin levels $(83,84)$. Pio treatment also lowered plasma FA levels, a good indication that FA flux to the liver fell (85). Both of these effects, as discussed earlier, should have been associated with reduced assembly and secretion of VLDL. What we do not know is whether lipogenesis was affected by Pio. Troglitazone (12), Rosi (53), and Pio (13) have all been shown to have modest effects on the ability of insulin to suppress hepatic glucose production, but effects of TZDs on hepatic lipid metabolism are less well described. Studies in $o b / o b$ and $d b / d b$ mice (86), A-ZIP total lipodystrophic mice (87), and brown adipose tissue-deficient (BATless) (88) mice, all models of insulin resistance, have demonstrated increased hepatic expression of PPAR $\gamma$ and increased hepatic lipogenesis. Further, several studies have provided compelling evidence that PPAR $\gamma$ plays a key role in regulating hepatic de novo lipogenesis in both insulin-resistant and normal mice (89-92). We propose, therefore, that Pio treatment, while improving glucose metabolism in adipose tissue, muscle, and even liver, may also stimulate expression of PPAR $\gamma$, as well as lipogenesis, in the liver. If lipogenesis were increased by Pio treatment, this might abrogate the effects that decreased FA flux and increased insulin-mediated apoB degradation would have on VLDL secretion. We realize that studies demonstrating reductions in hepatic fat (measured by magnetic resonance spectroscopy) in patients with T2DM after treatment with either Rosi (14) or Pio (83) argue against our proposal, but we would note that in both published studies $(14,83)$, hepatic TG mass after TZD treatment remained significantly above normal.

In summary, we have demonstrated that treatment with Pio for 14-16 weeks was associated with a significant reduction in VLDL findings of increased LPL mass in preheparin plasma and reduced apoC-III secretion, with concomitant reductions in plasma apoCIII levels, support increased LPL-mediated lipolysis as the basis for the fall in TG levels. Surprisingly, despite improvements in parameters of insulin sensitivity, neither VLDL TG nor VLDL apoB secretion from the liver was reduced. The failure of Pio treatment to reduce hepatic VLDL secretion requires further study.

\section{Methods}

Study subjects. Three male and 5 female patients with T2DM and dyslipidemia were enrolled in the study. The participants were patients of 2 of the investigators (D. Donovan and H.N. Ginsberg). T2DM was confirmed by past diagnosis and patients' present use of an oral hypoglycemic medicine. The glycemic treatment regimen had to be either monotherapy with a sulfonylurea or combination therapy with a sulfonylurea and metformin. Lipid inclusion criteria included plasma TG less than $600 \mathrm{mg} / \mathrm{dl}$, LDL cholesterol less than $140 \mathrm{mg} / \mathrm{dl}$, and HDL cholesterol less than $40 \mathrm{mg} / \mathrm{dl}$ for men and less than $50 \mathrm{mg} / \mathrm{dl}$ for women at screening in the absence of lipid-altering medications. None of the patients had another secondary cause of dyslipidemia, such as renal, hepatic, or untreated thyroid disease. None had any significant ischemic heart disease, according to prior history or a cardiac stress test performed within the past year. Female patients of childbearing capacity were excluded from the study, as were individuals using medications affecting lipid metabolism.

Study protocol. This was a single-blind, longitudinal, placebo-controlled trial of the effects of Pio on plasma lipid and lipoprotein metabolism in patients with T2DM. This study was approved by the Institutional Review

\section{Table 5}

Individual and mean levels of HDL apoA-I levels, apoA-I FSRs, and PRs during placebo and Pio treatments

\begin{tabular}{lcccccc}
\hline & \multicolumn{1}{c}{ HDL apoA-I } & \multicolumn{2}{c}{ HDL apoA-I FSR } & \multicolumn{2}{c}{ HDL apoA-I PR } \\
mg/kg/d
\end{tabular}

FSR, fractional synthetic rate in pool per day; PR into HDL is expressed as $\mathrm{mg} / \mathrm{kg} / \mathrm{d}$. 


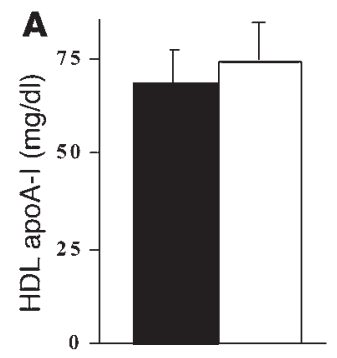

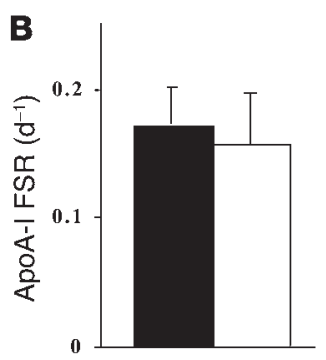

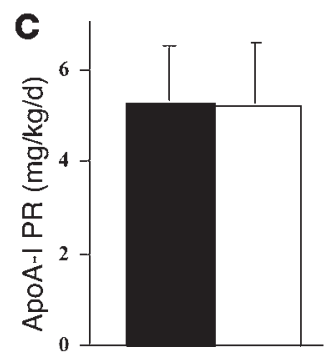

\section{Figure 6}

Mean levels \pm SD of HDL apoA-I (A), mean HDL apoA-I FSR (B), and mean HDL apoA-I PR (C) during placebo (black bars) and Pio (white bars) treatments. The results were derived from injection of $D_{3}$-leucine as a precursor of apoA-I. There were no significant effects of Pio treatment on the levels or metabolism of HDL apoA-I.

cal examination, and blood samples were obtained for chemistries and measurement of HbA1c levels, followed by a dinner consistent with the AHA Step 1 diet. Beginning at midnight ( 9 hours prior

Board of the Columbia University Medical Center (CUMC), and each subject consented to participate in the study prior to the start of the screening visit. After a telephone screening, potentially eligible patients came to the CUMC General Clinical Research Center (GCRC) outpatient unit after an overnight 12-14 hour fast. Blood was obtained for determination of a lipid profile (TC, TGs, HDL cholesterol, estimated LDL cholesterol, plasma glucose and HbA1c levels, liver and kidney function, and complete blood count. A history was taken and a physical examination performed, and potential subjects were questioned about inclusion/exclusion criteria.

One week later, patients who met the eligibility criteria were instructed by the GCRC dietitians to consume an American Heart Association (AHA) Step 1 diet. After an additional week ( 2 weeks after screening), all patients returned to the GCRC for fasting measurements of blood levels of lipids, lipoproteins, apolipoproteins, FAs, glucose, insulin, adiponectin, and $\mathrm{HbA1c}$. The dietitians provided further instructions regarding the AHA Step 1 diet. The patients were given placebo tablets and instructed to take 1 tablet per day. The patients had been informed, as part of the consent, that they would be receiving either placebo tablets or active Pio at different times during the study. During the study, patients were contacted frequently by the dietitians to ensure compliance with the protocol. They also monitored their glucose levels at home and reported them to the investigators each week in order to maintain stable plasma glucose levels. Daily activity and exercise were assessed several times to maintain stability.

After taking placebo tablets for 3 weeks, the patients were admitted to the GCRC inpatient unit for the first studies of their lipoprotein metabolism (TS1; see "Lipoprotein turnover protocol"). After TS1 was completed, the patients began to take $30 \mathrm{mg}$ of Pio, once daily. After 4 weeks, the dose of Pio was increased to $45 \mathrm{mg}$ daily. This dose was maintained for an additional 10-12 weeks. The patients continued to monitor their blood glucose levels at home, and the investigators reviewed the data weekly. Depending on results of home monitoring of glucose levels as well as those for HBA1c levels obtained at some of the visits to the GCRC, the dose of the sulfonylurea was changed in order to maintain constant glycemic control relative to the placebo period. The dose of metformin was not changed.

The patients visited the GCRC outpatient unit at the end of the third, sixth, ninth, twelfth, and either the thirteenth or fifteenth week of active Pio treatment, depending on their availability for TS2 testing. Each outpatient visit followed an overnight fast of 12-14 hours. Compliance with diet, exercise, and medication regimens was ascertained. Pulse, blood pressure, and weight were also measured, and patients were also examined for the presence of peripheral edema. Blood was also obtained at each visit for routine chemistries and blood counts and for measurement of plasma levels of lipids, lipoproteins, apolipoproteins, FAs, serum glucose, insulin, and adiponectin. HbA1c was measured at the ninth visit and between 12 and 15 weeks of Pio treatment. One week after either the thirteenth- or fifteenth-week visit, the patients were admitted again for TS2. The study ended at the completion of TS2 during week 14 or 16.

Lipoprotein turnover protocol. For both TS1 and TS2, patients were admitted to the GCRC inpatient unit in the late afternoon. They underwent a physi- to administration of tracers - see below), the patients consumed a liquid diet every 3 hours throughout the turnover study. The diet consisted of $75 \%$ carbohydrate and $25 \%$ protein and provided $60 \%$ of total daily calories calculated for each patient. This dietary regimen has been shown in numerous studies, by us and by others, to provide stable plasma levels of lipids, glucose, and hormones $(51,93)$.

On the morning of the second GCRC day, catheters were placed in bilateral antecubital veins: one was used for bolus injections of deuterium $3^{-}$ leucine ( $\mathrm{D}_{3}$-leucine), and $\mathrm{D}_{5}$-[ring] phenylalanine (Cambridge Isotope Laboratories Inc.), $1 \mathrm{mg} / \mathrm{kg}$ each, and $300 \mu \mathrm{Ci}\left[{ }^{3} \mathrm{H}\right]$ glycerol (PerkinElmer a constant infusion of $\mathrm{D}_{3}$-leucine, $1 \mathrm{mg} / \mathrm{kg} / \mathrm{h}$, for the next 15 hours. The other catheter was used for drawing blood samples at 18 time points: 0 , 10,20 , and 40 minutes and 1, 2, 3, 4, 6, 8, 10, 12, 15, 18, 24, 30, 36, and 48 hours. After the blood sampling at 48 hours, the patients had breakfast and were discharged. These samples were used for measurement of TG and cholesterol levels in plasma, VLDL, IDL, LDL, and HDL. They were also used for measurement of the enrichment of VLDL, IDL, and LDL apoB with $\mathrm{D}_{3}$-leucine and with $\mathrm{D}_{5}$-[ring] phenylalanine, the enrichment of HDL apoA-I with $\mathrm{D}_{3}$-leucine, and the specific radioactivity of VLDL $\left[{ }^{3} \mathrm{H}\right] \mathrm{TG}$. ApoC-III enrichment with $\mathrm{D}_{3}$-leucine was measured in plasma samples. Several timed serum samples were also saved to measure apoB, apoA-I, apoC-III, apoA-V, LPL, and HL concentrations.

Laboratory procedures. Plasma and lipoprotein cholesterol (Cholesterol/ HP Reagent; catalog 704036; Roche Diagnostics Corp.), plasma and lipoprotein TG (Triglycerides/GPO Reagent; 1488872; Roche Diagnostics Corp.), and serum glucose (Glucose/HK Reagent; 704035; Roche Diagnostics Corp.) levels were measured by standard enzymatic techniques on a Hitachi 704 automatic analyzer (Hitachi Ltd.). HDL was first isolated by precipitation of apoB-containing lipoproteins (HDL Cholesterol Precipitant; 543004; Roche Diagnostics Corp.). Serum insulin was measured by $\left[{ }^{125} \mathrm{I}\right]$ insulin radioimmunoassay (Coat-A-Count Insulin Assay; Diagnostic Products Corp.). Plasma FA level was determined by an enzymatic colorimetric method (NEFA C kit; Wako Chemicals USA Inc.) from an unthawed sample that had been frozen and stored at $-80^{\circ} \mathrm{C}$ immediately after centrifugation. HbA1c level was measured at CUMC's clinical laboratory (VARIANT II Hemoglobin A1c Program; catalog 270-2101; Bio-Rad Laboratories). Plasma adiponectin was measured by radioimmunoassay (Human Adiponectin RIA Kit; catalog HADP-61HK; Linco Research Inc.). Plasma and lipoprotein levels of apoB and apoA-I were assayed by immunonephelometry using apoB and apoA-I reagents (446650 and 446640, respectively; Beckman Coulter) and a Beckman Array System. ApoC-III levels were determined by an immunoturbidimetric method (411-35801; Wako Chemicals USA Inc.). Plasma apoA-V levels were determined by ELISA using an antibody raised against a human apoA-V synthetic peptide (94).

We determined LPL mass by ELISA using monoclonal antibodies against bovine milk LPL that cross-react with human LPL (95). Plates were coated overnight with $1 \mu \mathrm{g} /$ well of $4 \mathrm{~F} 9 \mathrm{mAb}$ in $0.1 \mathrm{M}$ carbonate-bicarbonate buffer, $\mathrm{pH}$ 9.6, washed with $0.05 \%$ Tween-20 in PBS (wash buffer), blocked Life and Analytical Sciences Inc.). The same catheter was used to deliver 
A

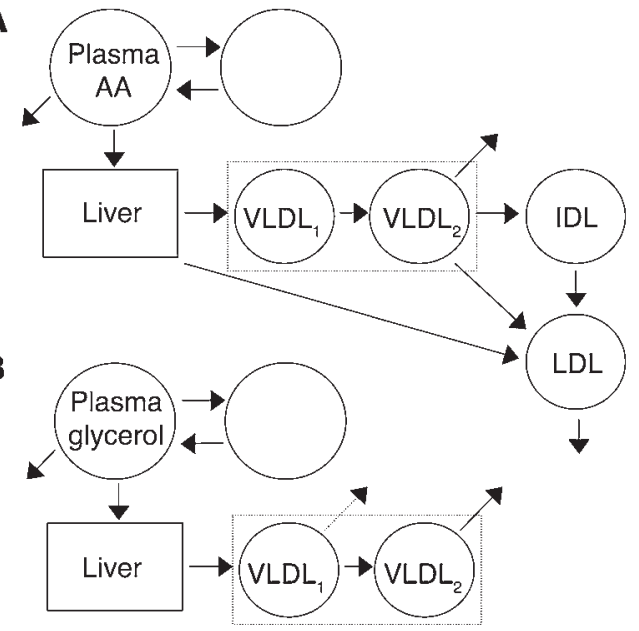

C

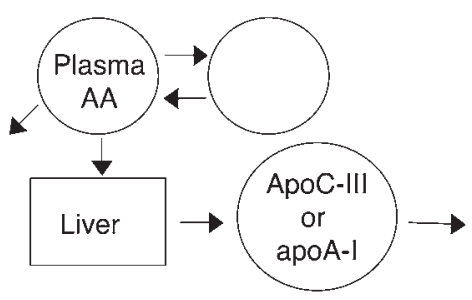

Figure 7

Multicompartmental model for apoB transport in VLDL, IDL, and LDL (A), TG transport in VLDL (B), and either HDL apoA-I transport or plasma apoC-III transport (C). The models were developed as described in Methods. Data for $\left[{ }^{3} \mathrm{H}\right]$ glycerol in VLDL TG and for deuterated apoB in VLDL, IDL, and LDL were fitted simultaneously. Data for deuterated apoA-I in HDL and apoC-III in plasma were fitted separately.

with $300 \mu \mathrm{l} /$ well of $1 \%$ BSA, $0.05 \%$ Tween 20, PBS pH 7.4 for 2 hours at room temperature and washed 3 times as before. Highly purified bovine milk LPL was employed as a standard. The samples were diluted with sample buffer (30\% glycerol, $2 \%$ BSA, $10 \mathrm{mM}$ sodium phosphate, $\mathrm{pH} 7.0$ ) to a final concentration of 0.24 guanidium hydrochloride and incubated in the wells overnight at $4^{\circ} \mathrm{C}$. Plates were washed 6 times with wash buffer and $\mathrm{mAb}$ conjugated to HRP was added for an overnight incubation at $4^{\circ} \mathrm{C}$. Plates were then washed 12 times before the HRP substrate was added. The plates were incubated at room temperature for 30 minutes and read at 490 $\mathrm{nm}$. The standard curve extended from 0.1 to $6 \mathrm{ng}$ per well. The standard curve was fitted to a quadratic function and yielded a correlation coefficient of 0.998 . The mean \pm SD for analyses of a pooled postheparin plasma sample, analyzed 8 times over a 1-month period, was $646 \pm 46 \mathrm{ng} / \mathrm{ml} \mathrm{LPL}$. HL was determined by a noncompetitive direct sandwich enzyme-linked immunosorbent assay (96). The assay uses 2 monoclonal antibodies, 1 for capture (XHL-3-6) and 1 for detection (XHL-1-6).

We isolated VLDL ( $d<1.006)$, IDL $(d, 1.006-1.019)$, LDL ( $d, 1.019-1.063)$, and $\operatorname{HDL}(d, 1.063-1.210)$ from turnover study plasma samples with a 50.3 Ti rotor ultracentrifuge (Beckman Coulter) using standard methods in our laboratory (97). ApoB and apoA-I were isolated by SDS gel electrophoresis and apoC-III by isoelectric focusing (79). Enrichment of each apolipoprotein with $\mathrm{D}_{3}$-leucine and $\mathrm{D}_{5}$-[ring] phenylalanine was measured by gas chromatography-mass spectrometry (GC-MS) after processing. Briefly, apolipoprotein bands were cut out of the gels, hydrolyzed in $12 \mathrm{M} \mathrm{HCl}$ at $110^{\circ} \mathrm{C}$ for 24 hours, and dried under nitrogen. To the dried samples, $250 \mu \mathrm{l}$ acetyl chloride/propanol solution was added, and the samples were capped and heated at $110^{\circ} \mathrm{C}$ for 1 hour and dried under nitrogen gas. Samples were then incubated with hepatafluorobutyric anhydride (HFBA; Sigma-Aldrich) at $60^{\circ} \mathrm{C}$ for 1 hour, the HFBA evaporated, and ethylacetate was added. The samples were centrifuged briefly to remove any precipitate, and the clear supernatants were transferred to clean vials and subjected to GC-MS using a 6890 Hewlett-Packard tabletop gas chromatograph and a 5973 Hewlett-Packard mass spectrometer, equipped with negative chemical ionization capability. The enrichment of plasma-free leucine and phenylalanine was assayed as well.

We measured $\left[{ }^{3} \mathrm{H}\right]$ glycerol-labeled TG from VLDL (isolated as described above) by extracting VLDL TGs with Zeolite (Sigma-Aldrich) in pure isopropyl alcohol (Mallinckrodt Baker Inc.) and counting radioactivity with biodegradable scintillation liquid (Ecoscint H; National Diagnostics) in a beta-scintillation counter (Tri-Carb 2300TR; Packard Instrument Company Inc.). We calculated TG-specific radioactivity after measuring VLDL TG concentrations in each sample (98).

Kinetic analyses. We analyzed ApoB turnover in VLDL, IDL, and LDL and TG turnover in VLDL using the $\mathrm{D}_{3}$-leucine and $\mathrm{D}_{5}$-[ring] phenylalanine enrichment data from the constant infusion and the bolus injection, respectively, along with the VLDL TG-specific radioactivity data generated by the injection of $\left[{ }^{3} \mathrm{H}\right]$ glycerol (99). A multicompartment model was adapted from our work with radiolabeled VLDL (97) and other published studies with leucine tracers (100) (Figure 7). ApoB and TG were required to have the same structure for VLDL and the same rate constants for the VLDL pools, but with different mass distributions. The minimum number of pools needed to fit the 9 sets of data (derived from 2 deuterium tracers, leucine and phenylalanine, in VLDL apoB, IDL apoB, LDL apoB, and plasma leucine and phenylalanine, plus ${ }^{3} \mathrm{H}-\mathrm{VLDL}-\mathrm{TG}$ ) simultaneously was chosen for the final model, shown in Figure 7. The data were fitted by least squares, giving equal weight to all data points (i.e., assuming a constant error variance for all measurements) using a computer program, Poolfit, developed by our group $(97,101)$, which solves the differential equations in closed form and computes the fits and parameter sensitivities as sums of exponentials. The fits yielded FCRs of apoB in VLDL, IDL, and LDL and VLDL TG FCR. The model also estimated rates of conversion of apoB between VLDL, IDL, and LDL. PRs were calculated by multiplying fractional catabolic rates by the measured apoB concentrations of the appropriate lipoprotein fractions.

We estimated ApoC-III and HDL apoA-I FSRs by fitting the leucine enrichment in plasma apoC-III and HDL apoA-I, respectively, with singlepool models (Figure 7), with the precursor enrichment set at the same level as found with the apoB model.

Statistical analysis. Paired Student's $t$ tests (SAS version 8; SAS Institute Inc.) were used to compare variables at the end of the placebo period with those at the end of the active medication period.

\section{Acknowledgments}

The authors wish to thank the nurses and the staffs of the Bionutrition, Bioinformatics, and Laboratory Cores of the CUMC GCRC for their dedicated support of these studies. This work was supported by an Investigator Initiated Grant from Takeda Pharmaceuticals North America Inc. and by NIH grants from the National Heart, Lung, and Blood Institute (grant HL 55368) and the National Center for Research Resources (grant RR00645).

Received for publication August 31, 2004, and accepted in revised form February 7, 2005.

Address correspondence to: Henry N. Ginsberg, Department of Medicine, PH 10-305, Columbia University, 630 West 168th Street, New York, New York 10032, USA. Phone: (212) 305-9562; Fax: (212) 305-3213; E-mail: hng1@columbia.edu. 
1. Kenny, S.J., Aubert, R.E., and Geiss, L.S. 1995. Prevalence and incidence of non-insulin-dependent diabetes. In Diabetes in America. 2nd edition. NIH. Bethesda, Maryland, USA. 47-68.

2. Geiss, L.S., Herman, W.H., and Smith, P.J. 1995 Mortality in non-insulin-dependent diabetes. In Diabetes in America. 2nd edition. NIH. Bethesda, Maryland, USA. 233-257.

3. Bierman, E.L. 1992. Atherogenesis in diabetes. Arterioscler. Thromb. Vasc. Biol. 12:647-656.

4. Ginsberg, H.N. 1991. Lipoprotein physiology in nondiabetic and diabetes states. Diabetes Care. 14:839-855.

5. Ginsberg, H.N., and Huang, L.-S. 2000. The insulin resistance syndrome: impact on lipoprotein metabolism and atherothrombosis. J. Cardiovasc. Risk. 7:325-331.

6. Ayyobi, A.F., and Brunzell, J.D. 2003. Lipoprotein distribution in the metabolic syndrome, type 2 diabetes mellitus, and familial combined hyperlipidemia. Am. J. Cardiol. 92:27j-33j.

7. Reaven, G.M., and Chen, Y.-D. 1988. Role of insulin in regulation of lipoprotein metabolism in diabetes. Diabetes Metab. Rev. 4:639-652.

8. Ginsberg, H.N. 2000. Insulin resistance and cardiovascular disease. J. Clin. Invest. 106:453-458.

9. Willson, T.M., Lambert, M.H., and Kliewer, S.A. 2001. Peroxisome proliferator-activated receptor gamma and metabolic disease. Annu. Rev. Biochem. 70:341-367.

10. Picard, F., and Auwerx, J. 2002. PPAR(gamma) and glucose homeostasis. Annu. Rev. Nutr. 22:167-197.

11. Zimmet, P. 2002. Addressing the insulin resistance syndrome: a role for the thiazolidinediones. Trends Cardiovasc. Med. 12:354-362.

12. Maggs, D.G., et al. 1998. Metabolic effects of troglitazone monotherapy in type 2 diabetes mellitus. A randomized, double-blind, placebo-controlled trial. Ann. Intern. Med. 128:176-185.

13. Miyazaki, Y., et al. 2002. Effect of pioglitazone on abdominal fat distribution and insulin sensitivity in type 2 diabetic patients. J. Clin. Endocrinol. Metab. 87:2784-2791.

14. Mayerson, A.B., et al. 2002. The effects of rosiglitazone on insulin sensitivity, lipolysis, and hepatic and skeletal muscle triglyceride content in patients with type 2 diabetes. Diabetes. 51:797-802.

15. Racette, S., Davis, A., McGill, J., and Klein, S. 2002. Thiazolidinediones enhance insulin-mediated suppression of fatty acid flux in type 2 diabetes mellitus. Metabolism. 51:169-174.

16. Ginsberg, H.N., Plutzky, J., and Sobel, B.E. 1999. A review of metabolic and cardiovascular effects of oral antidiabetic agents: beyond glucose-level lowering. J. Cardiovasc. Risk. 6:337-347.

17. Freed, M.I., et al. 2002. Effects of rosiglitazone alone and in combination with atorvastatin on the metabolic abnormalities in type 2 diabetes mellitus. Am. J. Cardiol. 90:947-952.

18. LaCivita, K.A., and Villarreal, G. 2002. Differences in lipid profiles of patients given rosiglitazone followed by pioglitazone. Curr. Med. Res. Opin. 18:363-370.

19. Boyle, P.J., et al. 2002. Effects of pioglitazone and rosiglitazone on blood lipid levels and glycemic control in patients with type 2 diabetes mellitus: a retrospective review of randomly selected medical records. Clin. Ther. 24:378-396.

20. Ginsberg, H.N., et al. 1986. Apolipoprotein $\mathrm{B}$ metabolism in subjects with deficiency of apolipoprotein C-III and A-I: evidence that apolipoprotein C-III inhibits lipoprotein lipase in vivo. J. Clin. Invest. 78:1287-1295.

21. Pennacchio, L.A., et al. 2001. An apolipoprotein influencing triglycerides in humans and mice revealed by comparative sequencing. Science. 294:169-172.

22. Ruotolo, G., and Howard, B.V. 2002. Dyslipidemia of the metabolic syndrome. Curr. Cardiol. Rep.
4:494-500

23. Bagdade, J.D., Porte, D., and Bierman, E.L. 1967. Diabetic lipemia: a form of acquired fat-induced lipemia. N. Engl. J. Med. 276:427-433.

24. Fisher, E.A., and Ginsberg, H.N. 2002. Complexity in the secretory pathway: the assembly and secretion of apolipoprotein B-containing lipoproteins. J. Biol. Chem. 277:17377-17380.

25. Ginsberg, H.N. 1987. Very low density lipoprotein metabolism in diabetes mellitus. Diabetes Metab. Rev. 3:571-589.

26. Cummings, M.H., et al. 1995. Increased hepatic secretion of very-low-density lipoprotein apolipoprotein B-100 in NIDDM. Diabetologia. 38:959-967.

27. Chan, D.C., Watts, G.F., Redgrave, T.G., Mori, T.A., and Barrett, H.R. 2002. Apolipoprotein B-100 kinetics in visceral obesity; associations with plasma apolipoprotein C-III concentration. Metabolism. 51:1041-1046

28. Laws, A., et al. 1997. Differences in insulin suppression of free fatty acid levels by gender and glucose tolerance status. Relation to plasma triglyceride and apolipoprotein B concentrations. Insulin Resistance Atherosclerosis Study (IRAS) Investigators. Artheroscler. Thromb. Vasc. Biol. 17:64-71.

29. Howard, B.V., Reitman, J.S., Vasquez, B., and Zech, L. 1983. Very-low density lipoprotein triglyceride metabolism in non-insulin-dependent diabetes mellitus: relationship to plasma insulin and free fatty acids. Diabetes. 32:271-276.

30. Yki-Jarvinen, H., and Taskinen, M.-R. 1988. Interrelationship among insulin's antilipolytic and glucoregulatory effects and plasma triglycerides in nondiabetic and diabetic patients with endogenous hypertriglyceridemia. Diabetes. 37:1271-1278.

31. Castro Cabezas, M., et al. 1993. Impaired fatty acid metabolism in familial combined hyperlipidemia. A mechanism associating hepatic apolipoprotein $\mathrm{B}$ overproduction and insulin resistance. J. Clin. Invest. 92:160-168.

32. Haemmerle, G., et al. 2002. Hormone-sensitive lipase deficiency in mice changes the plasma lipid profile by affecting the tissue-specific expression pattern of lipoprotein lipase in adipose tissue and muscle. J. Biol. Chem. 277:12946-12952.

33. Zhang, Y.-L., et al. 2004. Regulation of hepatic apolipoprotein B-lipoprotein assembly and secretion by the availability of fatty acids. I. Differential response to the delivery of fatty acids via albumin or remnant-like emulsion particles. J. Biol. Chem. 279:19362-19374.

34. Lewis, G.F., Uffelman, K.D., Szeto, L.W., Weller, B., and Steiner, G. 1995. Interaction between free fatty acids and insulin in the acute control of very low density lipoprotein production in humans. J. Clin. Invest. 95:158-166.

35. Sparks, J.D., and Sparks, C.E. 1994. Insulin regulation of triacylglycerol-rich lipoprotein synthesis and secretion. Biochim. Biophys. Acta. 1215:9-32.

36. Sparks, J.D., Phung, T.L., Bolognino, M., and Sparks, C.E. 1996. Insulin-mediated inhibition of apolipoprotein B secretion requires an intracellular trafficking event and phosphatidylinositol 3-kinase activation: studies with brefeldin A and wortmannin in primary cultures of rat hepatocytes. Biochem. 313:567-574.

37. Sparks, J.D., and Sparks, C.E. 1994. Obese Zucker $(\mathrm{fa} / \mathrm{fa})$ rats are resistant to insulin's inhibitory effect on hepatic apo B secretion. Biochem. Biophys. Res. Commun. 205:417-422.

38. Taghibiglou, C., et al. 2000. Mechanisms of hepatic very low density lipoprotein overproduction in insulin resistance. Evidence for enhanced lipoprotein assembly, reduced intracellular apoB degradation, and increased microsomal triglyceride transfer protein in a fructose-fed hamster model. J. Biol. Chem. 275:8416-8425.
39. Lewis, G.F., Uffelman, K.D., Szeto, L.W., and Steiner, G. 1993. Effects of acute hyperinsulinemia on VLDL triglyceride and VLDL apoB production in normal weight and obese individuals. Diabetes. 42:833-842.

40. Malmstrom R., et al. 1997. Defective regulation of triglyceride metabolism by insulin in the liver in NIDDM. Diabetologia. 40:454-462.

41. Aarsland, A., Chinkes, D., and Wolfe, R.R. 1996. Contributions of de novo synthesis of fatty acids to total VLDL-triglyceride secretion during prolonged hyperglycemia/hyperinsulinemia in normal man. J. Clin. Invest. 98:2008-2017.

42. Hellerstein, M.K., et al. 1991. Measurement of de novo hepatic lipogenesis in humans using stable isotopes. J. Clin. Invest. 87:1841-1852.

43. Diraison, F., and Beylot, M. 1998. Role of human liver lipogenesis and reesterificaton in triglycerides secretion and in FFA reesterification. Am. J. Physiol. 274:E321-E327.

44. Shimomura, I., et al. 1999. Insulin selectively increases SREBP-1c mRNA in the livers of rats with streptozotocin-induced diabetes. Proc. Natl. Acad. Sci. U. S. A. 96:13656-13661.

45. Elam, M.B., et al. 2001. Increased hepatic VLDL secretion, lipogenesis, and SREBP-1 expression in the corpulent JCR:LA-cp rat. J. Lipid Res. 42:2039-2048.

46. Shimomura, I., et al. 2000. Decreased IRS-2 and increased SREBP-1c lead to mixed insulin resistance and sensitivity in livers of lipodystrophic and ob/ob mice. Mol. Cell. 6:77-86.

47. Ono, H., et al. 2003. Hepatic Akt activation induces marked hypoglycemia, hepatomegaly, and hypertriglyceridemia with sterol regulatory element binding protein involvement. Diabetes. 52:2905-2913.

48. Borradaile, N.M., de Dreu, L.E., and Huff, M.W. 2003. Inhibition of net HepG2 cell apolipoprotein $B$ secretion by the citrus flavonid naringenin involves activation of phosphatidylinositol 3-kinase, independent of insulin receptor substrate-1 phosphorylation. Diabetes. 52:2554-2561.

49. Matsuzaka, T., et al. 2004. Insulin-independent induction of sterol regulatory element-bindingprotein-1c expression in the livers of streptozotocin-treated mice. Diabetes. 53:560-569.

50. Janus, E.D., Nicoll, A.M., Turner, P.R., Magill, P., and Lewis, B. 1980. Kinetic bases of the primary hyperlipidemias: studies of apolipoprotein B turnover in genetically defined subjects. Eur. J. Clin. Invest. 10:161-172.

51. Kesaniemi, Y.A., Beltz, W.F., and Grundy, S.M. 1985. Comparisons of metabolism of apolipoprotein B in normal subjects, obese patients, and patients with coronary heart disease. J. Clin. Invest. 76:586-595.

52. Boden, G., Cheung, P., Mozzoli, M., and Fried, S.K. 2003. Effect of thiazolidinediones on glucose and fatty acid metabolism in patients with type 2 diabetes. Metabolism. 52:753-759.

53. Miyazaki,Y., et al. 2001. Effect of rosiglitazone on glucose and non-esterified fatty acid metabolism in type II diabetic patients. Diabetologia. 44:2210-2219.

54. Kakuma, T., et al. 2000. Leptin, troglitazone, and the expression of sterol regulatory element binding proteins in liver and pancreatic islets. Proc. Natl. Acad. Sci. U. S. A. 97:8536-8541.

55. Carpentier, A., et al. 2002. Ameliorated hepatic insulin resistance is associated with normalization of microsomal triglyceride transfer protein expression and reduction in very low density lipoprotein assembly and secretion in the fructose-fed hamster. J. Biol. Chem. 277:28795-28802.

56. Schoonjans, K., et al. 1996. PPARalpha and PPARgamma activators direct a distinct tissue-specific transcriptional response via a PPRE in the lipoprotein lipase gene. EMBO J. 15:5336-5348.

57. Sunayama, S., et al. 1999. Effects of troglitazone 
on atherogenic lipoprotein phenotype in coronary patients with insulin resistance. Atherosclerosis. 146:187-193.

58. Shirai, K., et al. 1999. The effect of insulin sensitizer, troglitazone, on lipoprotein lipase mass in preheparin serum. Diabetes Res. Clin. Pract. 46:35-41.

59. Kobayashi, J., et al. 1999. Effect of troglitazone on plasma lipid metabolism and lipoprotein lipase. Br. J. Clin. Pharmacol. 47:433-439.

60. Hirano, T., Nishioka, F., and Murakami, T. 2004. Measurement of the serum lipoprotein lipase concentration is useful for studying triglyceride metabolism: comparison with postheparin plasma. Metabolism. 53:526-531.

61. Kobayashi, J., et al. 2001. Pre-heparin plasma lipoprotein lipase mass: correlation with intra-abdominal visceral fat accumulation. Horm. Metab. Res. 33:412-416

62. Kageyama, H., et al. 2003. Lipoprotein lipase mRNA in white adipose tissue but not in skeletal muscle is increased by pioglitazone through PPARgamma. Biochem. Biophys. Res. Commun. 305:22-27.

63. Bogacka, I., Xie, H., Bray, G.A., and Smith, S.R. 2004. The effect of pioglitazone on peroxisome proliferator-activated receptor-gamma target genes related to lipid storage in vivo. Diabetes Care. 27:1660-1667.

64. Brown, W.V., and Baginsky, M.L. 1972. Inhibition of lipoprotein lipase by an apoprotein of human very low density lipoprotein. Biochem. Biophys. Res. Commun. 46:375-381.

65. Aalto-Setala, K., et al. 1992. Mechanism of hypertriglyceridemia in human apolipoprotein (apo) CIII transgenic mice: diminished very low density lipoprotein fractional catabolic rate associated with increased apo CIII and reduced apoE on the particles. J. Clin. Invest. 90:1889-1900.

66. Maeda, N., et al. Targeted disruption of the apolipoprotein C-III gene in mice results in hypotriglyceridemia and protection from postprandial hypertriglyceridemia. J. Biol. Chem. 269:23610-23616.

67. Staels, B., et al. 1998. Mechanism of action of fibrates on lipid and lipoprotein metabolism. Circulation. 98:2088-2093.

68. Coste, H., and Rodriguez, J.C. 2002. Orphan nuclear hormone receptor Rev-erbalpha regulates the human apolipoprotein CIII promoter. J. Biol. Chem. 277:27120-27129.

69. Hertz, R., Bishara-Shieban, J., and Bar-Tana, J. 1995. Mode of action of peroxisome proliferators in hypolipidemic drugs. Suppression of apolipoprotein C-III. J. Biol. Chem. 270:13470-13475.

70. Raspe, E., et al. 2001. Transcriptional regulation of apolipoprotein C-III gene expression by the orphan nuclear receptor RORalpha. J. Biol. Chem. 276:2865-2871.

71. Malmendier, C.L., et al. 1989. Apolipoproteins C-II and C-III metabolism in hypertriglyceridemic patients. Effect of a drastic triglyceride reduction by combined diet restriction and fenofibrate administration. Atherosclerosis. 77:139-149.

72. Sakamoto, J., et al. 2000. Activation of human peroxisome proliferator-activated receptor (PPAR) subtypes by pioglitazone. Biochem. Biophys. Res. Commun. 278:704-711.

73. Altomonte, J., et al. 2004. Foxo1 mediates insu- lin action on apoC-III and triglyceride metabolism. J. Clin. Invest. 114:1493-1503. doi:10.1172/ JCI200419992.

74. Chen, M., Breslow, J.L., Li, W., and Leff, T. 1994. Transcriptional regulation of the apoC-III gene by insulin in diabetic mice: correlation with changes in plasma triglyceride levels. J. Lipid Res. 35:1918-1924.

75. Li, W.W., et al. 1995. Common genetic variation in the promoter of the human apo CIII gene abolishes regulation by insulin and may contribute to hypertriglyceridemia. J. Clin. Invest. 96:2601-2605.

76. Cohn, J.S., Patterson, B.W., Uffelman, K.D., Davignon, J., and Steiner, G. 2004. Rate of production of plasma and very-low-density lipoprotein (VLDL) apolipoprotein C-III is strongly related to the concentration and level of production of VLDL triglyceride in male subjects with different body weights and levels of insulin sensitivity. J. Clin. Endocrinol. Metab. 89:3949-3955.

77. Bajaj, M., Suraamornkul, S., Hardies, L.J., Pratipanawatr, T., and Defronzo, R.A. 2004. Plasma resistin concentration, hepatic fat content, and hepatic and peripheral insulin resistance in pioglitazone-treated type II diabetic patients. Int. J. Obes. Relat. Metab. Disord. 28:783-789.

78. Mar, R., et al. 2004. Association of the apolipoprotein A1/C3/A4/A5 gene cluster with triglyceride levels and LDL particle size in familial combined hyperlipidemia. Circ. Res. 94:993-999.

79. Vu-Dac, N., et al. 2003. Apolipoprotein A5, a crucial determinant of plasma triglyceride levels, is highly responsive to peroxisome proliferatoractivated receptor alpha activators. J. Biol. Chem. 278:17982-17985

80. Hanefeld, M., et al. 2004. One-year glycemic control with a sulfonylurea plus pioglitazone versus a sulfonylurea plus metaformin in patients with type 2 diabetes. Diabetes Care. 27:141-147.

81. Akiyama, T.E., et al. 2002. Conditional disruption of the peroxisome proliferator-activated receptor gamma gene in mice results in lowered expression of ABCA1, ABCG1, and apoE in macrophages and reduced cholesterol efflux. Mol. Cell. Biol. 22:2607-2619.

82. Argmann, C.A., Sawyez, C.G., McNeil, C.J., Hegele, R.A., and Huff, M.W. 2003. Activation of peroxisome proliferator-activated receptor gamma and retinoid $X$ receptor results in net depletion of cellular cholesterylesters in macrophages exposed to oxidized lipoproteins. Arterioscler. Thromb. Vasc. Biol. 23:475-482.

83. Bajaj, M., et al. 2004. Decreased plasma adiponectin concentrations are closely related to hepatic fat content and hepatic insulin resistance in pioglitazone-treated type 2 diabetes patients. J. Clin. Endocrinol. Metab. 89:200-206.

84. Pajvani, U.B., and Scherer, P.E. 2003. Adiponectin: systemic contributor to insulin sensitivity. Curr Diab. Rep. 3:207-213.

85. Havel, R.J., Kane, J.P., Balasse, E.O., Segel, N., and Basso, L.V. 1970. Splanchnic metabolism of free fatty acids and production of triglycerides of very low density lipoproteins in normotriglyceridemic and hypertriglyceridemic human. J. Clin. Invest. 49:2017-2035.

86. Memon, R.A., et al. 2000. Up-regulation of peroxisome proliferator-activated receptors (PPAR-a) and
PPAR-u messenger ribonucleic acid expression in the liver in murine obesity: troglitazone induces expression of PPAR-u-responsive adipose tissuespecific genes in the liver of obese diabetic mice. Endocrinology. 141:4021-4031.

87. Moitra, J., et al. 1998. Life without white fat: a transgenic mouse. Genes Dev. 12:3168-3181.

88. Vidal-Puig, A., et al. 1996. Regulation of PPAR gamma gene expression by nutrition and obesity in rodents. J. Clin. Invest. 97:2553-2561.

89. Chao, L., et al. 2000. Adipose tissue is required for the antidiabetic, but not for the hypolipidemic, effect of thiazolidinediones. J. Clin. Invest. 106:1221-1228.

90. Gavrilova, O., et al. 2003. Liver peroxisome proliferator-activated receptor gamma contributes to hepatic steatoisis, triglyceride clearance, and regulation of body fat mass. J. Biol. Chem. 278:34268-34276.

91. Matsusue, K., et al. 2003. Liver-specific disruption of PPAR $\gamma$ in leptin-deficient mice improves fatty liver but aggravates diabetic phenotypes. J. Clin. Invest. 111:737-747. doi:10.1172/JCI200317223.

92. Herzig, S., et al. 2003. CREB controls hepatic lipid metabolism through nuclear hormone receptor PPAR-gamma. Nature. 426:190-193.

93. Ginsberg, H.N., Jacobs, A., Le, N.-A., and Sandler, J. 1982. Effect of somatostatin-induced suppression of postprandial insulin response upon the hypertriglyceridemia associated with a high carbohydrate diet. J. Clin. Invest. 70:1225-1233.

94. Fruchart-Najib, J., et al. 2004. Mechanism of triglyceride lowering in mice expressing human apolipoprotein A5. Biochem. Biophys. Res. Commun. 319:397-404.

95. Peterson, J., Fujimoto, W.Y., and Brunzell, J.D. 1992. Human lipoprotein lipase: relationship of activity, heparin affinity, and conformation as studied with monoclonal antibodies. J. Lipid Res. 33:1165-1170.

96. Bensadoun, A. 1996. Sandwich immunoassay for measurement of human hepatic lipase. Methods Enzymol. 263:333-338.

97. Arad, Y., Ramakrishnan, R., and Ginsberg, H.N. 1990 Lovastatin therapy reduces low density lipoprotein apoB levels in subjects with combined hyperlipidemia by reducing the production of apoB-containing lipoproteins: implications for the pathophysiology of apoB production. J. Lipid Res. 31:567-582.

98. Ginsberg, H.N., Le, N.-A., and Gibson, J.C. 1985. Regulation of the production and catabolism of plasma low density lipoproteins in hypertriglyceridemic subjects. Effect of weight loss. J. Clin. Invest. 75:614-623.

99. Melish, J., Le, N.-A., Ginsberg, H., Steinberg, D., and Brown, W.V. 1980. Dissociation of triglyceride and apoprotein-B production in very low density lipoproteins. Am. J. Physiol. 239:E354-E362.

100.Adiels, M., et al. 2005. A new combined multicompartmental model for apolipoprotein B-100 and triglyceride metabolism in VLDL subfractions. J. Lipid Res. 46:58-67.

101. Berglund, L., et al. 1998. Three-fold effect of lovastatin treatment on low density lipoprotein metabolism in subjects with hyperlipidemia: increase in receptor activity, decrease in apoB production, and decrease in particle affinity for the receptor. Results from a novel triple-tracer approach. J. Lipid Res. 39:913-924. 